\title{
Diabetic Patients Who Smoke: Are They Different?
}

\author{
Leif I. Solberg, $M D^{1}$ \\ Jay R. Desai, $\mathrm{MPH}^{2}$ \\ Patrick J. O'Connor, MD, MPH \\ Donald B. Bishop, PbD \\ Heather M. Devlin, $M A^{2}$ \\ 'HealthPartners Research Foundation, \\ Minneapolis, Minn \\ ${ }^{2}$ Minnesota Department of Health, \\ St. Paul, Minn
}

Conflicts of interest: none reported

\section{CORRESPONDING AUTHOR}

Leif I. Solberg, MD

HealthPartners Research Foundation

PO Box 1524, Minneapolis MN 55440 leif.i.solberg@healthpartners.com

\begin{abstract}
BACKGROUND We wanted to identify differences between diabetic patients who smoke and those who do not smoke to design more effective strategies to improve their diabetes care and encourage smoking cessation.

METHODS A random sample of adult health plan members with diabetes were mailed a survey questionnaire, with telephone follow-up, asking about their attitudes and behaviors regarding diabetes care and smoking. Among the 1,352 respondents (response rate $82.4 \%$ ), we found 188 current smokers whose answers we compared with those of 1,264 nonsmokers, with statistical adjustment for demographic characteristics and duration of diabetes.
\end{abstract}

RESULTS Smokers with diabetes were more likely to report fair or poor health (odds ratio $[\mathrm{OR}]=1.5, P=.03$ ) and often feeling depressed $(\mathrm{OR}=1.7, P=$ .004). Relative to nonsmokers, smokers had lower rates of checking blood glucose levels, were less physically active, and had fewer diabetes care visits, glycated hemoglobin $\left(A_{1 c}\right)$ tests, foot examinations, eye examinations, and dental checkups $(P \leq .01)$. Smokers also reported receiving and desiring less support from family and friends for specific diabetic self-management activities and had lower readiness to quit smoking than has been observed in other population groups.

CONCLUSIONS Clinicians should be aware that diabetic patients who smoke are more likely to report often feeling depressed and, even after adjusting for depression, are less likely to be active in self-care or to comply with diabetes care recommendations. Diabetic patients who smoke are special clinical challenges and are likely to require more creative and consistent clinical interventions and support.

Ann Fam Med 2004;2:26-32. DOI: 10.1370/afm.36.

\section{INTRODUCTION}

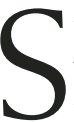
moking has long been known to worsen the prognosis of patients with diabetes. Mulhauser's literature review in $1990^{1}$ concluded that the frequency of smoking in adults with diabetes was comparable to that in the general population and that smoking is a major risk factor for both macrovascular and microvascular complications. Subsequent systematic reviews have strengthened these conclusions while adding evidence that smoking increases insulin resistance, worsens diabetes control, and may even induce the disease. ${ }^{2,3}$ Many cross-sectional and prospective studies of patients who have diabetes also show that cardiovascular and all-cause mortality is higher in those who smoke than in those who do not smoke. ${ }^{4-7}$ Thus, the 1 in 5 persons with diabetes who also smoke represent a particularly important target for intervention, both by clinicians and by policy makers in health plans and public health.

Despite this information, and despite strong evidence that clinician support of smoking cessation is effective for smokers among the general population and those with diabetes, ${ }^{8-10}$ only $58 \%$ of patients with diabetes who smoke reported that a physician had ever advised them to stop or cut down on their smoking. ${ }^{11}$ Recently, the American Diabetes Associa- 
tion noted that "smoking cessation has not received the priority it deserves from health care providers" and recommended that identification of smoking status and systematic cessation support "should be incorporated into the routine practice of diabetes care." ${ }^{12}$

In the past, many diabetes care specialists and some professional organizations have concentrated largely on glucose-oriented diabetes care strategies. ${ }^{13}$ Recent evidence shows that cardiovascular disease risk management might be more important than tight glycemic control in reducing morbidity and mortality in patients with diabetes. ${ }^{14-17}$ These new data, however, have only recently received strong emphasis in the general medical literature. ${ }^{18,19}$ Enthusiasm for smoking cessation as an important diabetes care component has also been constrained by the assumption that smokers who have diabetes are less interested in quitting than those who do not have diabetes and that smoking reflects their lack of interest in health promotion, prevention, and selfcare strategies. ${ }^{20}$ Providers who sense this attitude might avoid addressing smoking, finding it difficult enough to deal with other aspects of diabetes care. Because it has been shown that smokers who have diabetes are much more likely to be in a precontemplation stage for quitting and are also more likely to have depression, such reduced interest in their health seems likely. ${ }^{21,22}$

We report a cross-sectional analysis of adult health plan members with diabetes that compares self-reports of health attitudes and diabetes care behaviors between smokers and nonsmokers. We hypothesized that diabetic respondents who smoked would have worse glycemic control and less interest in self-care or support from others for all aspects of their diabetes care.

\section{METHODS}

This study was conducted at HealthPartners, a Minnesota health plan that provided care to about 700,000 members in 1996. All aspects of the study methods were reviewed and approved (after modifications) by the Institutional Review Board. We used a previously validated method with estimated sensitivity of 0.91 and positive predictive value of 0.94 to identify adult health plan members with diabetes. ${ }^{23}$ From this pool of about 14,000 adult members with diabetes, we drew a random sample of 1,828 study subjects, one half from those receiving care in the HealthPartners Medical Group and one half from those receiving care from any of 50 contracted private medical groups

We constructed a 16-page, 116 -item questionnaire of attitudes and behaviors related to diabetes care, building it largely from questions in other validated and reliable surveys. We pretested the questionnaire, modified it, and sent to the study sample, using a variation of the Dillman Total Design Method with telephone follow-up. ${ }^{24}$ Completed questionnaires were received from 1,565 members for a response rate of $85.6 \%$. Only 1,352 respondents $(74.0 \%)$, however, answered all of the questions required for this analysis. A comparison of the 213 incomplete questionnaires with the 1,352 completed ones for the questions that allowed comparison showed that the 213 respondents who returned incomplete questionnaires had the same rate of smoking (13.9\% vs $13.3 \%, P=.81)$ and were similar on most other questions. These 213 respondents tended to be somewhat older, less educated, even more likely to report often feeling depressed, and less likely to have had at least 1 diabetes visit and 1 glycated hemoglobin $\left(\mathrm{A}_{1 \mathrm{c}}\right)$ test in the past year.

About $12 \%$ of all respondents reported onset of diabetes before the age of 30 years and treatment exclusively with insulin. Thus, at least $88 \%$ of the respondents were likely to have type- 2 diabetes. Patients with type 1 and type 2 diabetes were pooled for analysis because it is difficult to distinguish these groups from their responses to a survey and because key clinical recommendations, such as goals for $A_{1 \mathrm{c},}$ low-density lipoprotein cholesterol, and blood pressure treatment, are the same for all patients. ${ }^{25}$

For a subgroup of 602 patients who received care from HealthPartners Medical Group, we were also able to obtain $A_{1 c}$ values during the year before and after the survey. These patients had all $\mathrm{A}_{1 \mathrm{c}}$ laboratory tests done at a single accredited clinical chemistry laboratory using a standard liquid chromatographic method with a normal range of $4.5 \%$ to $6.1 \%$ and a coefficient of variation of $0.58 \%$ at an $\mathrm{A}_{1 \mathrm{c}}$ value of $8.8 \% .{ }^{26}$ Where multiple results were present for 1 patient, the result closest in time to the survey was used.

We first compared 3 groups for the characteristics and behaviors of interest: current smokers, former smokers, and never smokers. Age and age-related measures, such as diabetes duration and comorbidities, were the primary differences between former smokers and never smokers. These 2 groups were similar for most other measures of interest. Because, in a busy practice, clinicians are likely to know only whether a patient is a current smoker, and because our analyses adjusted for age and duration of diabetes, we combined former and never smokers for these analyses and compared the responses of these 2 groups (current smokers vs never or former smokers) on questions and scales relevant to the hypotheses using chi square and the $t$ test.

We then constructed multivariate linear regression models and logistic regression models to control for differences between the groups in variables believed likely to affect the responses. These factors were age, sex, race, education, marital status, duration of diabe- 


\begin{tabular}{|c|c|c|c|}
\hline Characteristic & $\begin{array}{l}\text { Smokers } \\
(n=188)\end{array}$ & $\begin{array}{l}\text { Nonsmokers } \\
(\mathrm{n}=1,164)\end{array}$ & $P$ Value \\
\hline Mean age (y) & $52.6 \pm 12.6$ & $58.4 \pm 14.8$ & $<.001$ \\
\hline Male, \% & 48.4 & 51.2 & .48 \\
\hline White, \% & 90.4 & 91.0 & .81 \\
\hline $\begin{array}{l}\text { Education } \geq \text { high } \\
\text { school, \% }\end{array}$ & 56.9 & 64.1 & .059 \\
\hline Married, \% & 67.6 & 71.5 & .27 \\
\hline $\begin{array}{l}\text { Employed for } \\
\text { wages, \% }\end{array}$ & 59.0 & 43.9 & $<.001$ \\
\hline
\end{tabular}

tes, insulin use, type of medical group (owned vs contracted), and method of response to the survey (mail vs telephone). Each survey response item was treated as the dependent variable, and the covariates above were entered in the regression analysis along with smoking status. The adjusted coefficient and odds ratio for smoking status was interpreted for each variable reported in the results tables. Finally, because many of the findings could have been caused by depression, we tested whether the proportion who agreed or strongly agreed with the question, "I often feel sad or depressed," affected the significant differences found between smokers and nonsmokers.

\section{RESULTS}

Smokers made up $13.9 \%$ of the respondents to this survey of patients with diabetes. Their demographic characteristics are compared with those of the nonsmokers in Table 1. Smokers and nonsmokers were demographically similar except that smokers were significantly younger and more likely to be employed. Table 2 shows that smokers also had diabetes diagnosed at a younger age. Among the subgroup of 602 with $A_{1 c}$ values, the proportion with $A_{1 c}<7 \%$ or $>9.5 \%$ was similar for smokers and nonsmokers, although there were only 24 and 18 smokers, respectively, in these groups. The same proportion of each group (55\% to $60 \%$ ) also reported that their diabetes had been well controlled for the past 6 months. When adjusted for other characteristics, smokers were $50 \%$ more likely to report being in fair or poor health and were even more likely to report often feeling depressed or having mental health visits in the last year. On the other hand, smokers were somewhat less likely to report being obese or having hypertension.

Only $20.2 \%$ of current smokers were in the preparation stage of readiness to quit smoking (considering quitting in the next 30 days), while $28.7 \%$ were in the contemplation stage (considering quitting in the next 1 to 6 months) and $51.1 \%$ were in precontemplation (no interest in quitting). Readiness stage was not significantly associated with any of the demographic characteristics of smokers except that those with less interest in quitting had diabetes diagnosed with at older ages. Approximately $85 \%$ reported that a health professional had cautioned them about the added risk of smoking with diabetes, and the same percentage recalled receiving advice about smoking. Smokers in the preparation stage for quitting were no more likely to report either type of advice than were those in contemplation or precontemplation stages. Overall, $56 \%$ of the smokers smoked at least 1 pack a day, and $24 \%$ reported smoking their first cigarette within 5 minutes of awakening in the morning. Nevertheless, $77 \%$ reported a quit attempt in the past year, and $26 \%$ reported a quit attempt that lasted more than a week.

Table 3 compares diabetes self-care behaviors reported by smokers and nonsmokers. Smokers were

Table 2. Health Characteristics of Respondents by Smoking Status

\begin{tabular}{|c|c|c|c|c|c|}
\hline Characteristic & $\begin{array}{c}\text { Smokers } \\
(n=188)\end{array}$ & $\begin{array}{l}\text { Nonsmokers } \\
(n=1,164)\end{array}$ & $P$ value & $\begin{array}{l}\text { Adjusted OR* } \\
(95 \% \mathrm{Cl})\end{array}$ & $\begin{array}{l}\text { Adjusted } \\
P \text { Value* }\end{array}$ \\
\hline Mean age at diagnosis (y) & $42.8 \pm 15.9$ & $47.6 \pm 17.8$ & $<.001$ & & \\
\hline Duration of diabetes (y) & $9.7 \pm 9.7$ & $10.8 \pm 9.9$ & .18 & & \\
\hline Use insulin, \% & 49.5 & 46.1 & .40 & & \\
\hline Latest $A_{1 c}(n=602)$ & $8.3\left(8.7^{*}\right)$ & $8.3(8.9 *)$ & .92 & & $<.001$ \\
\hline Fair or poor health, \% & 30.3 & 26.2 & & $1.47(1.03-2.10)$ & .033 \\
\hline Obese by BMI, \% & 38.0 & 41.5 & & $0.68(0.47-0.97)$ & .047 \\
\hline Diagnosed heart trouble, \% & 15.4 & 26.8 & & $0.68(0.44-1.07)$ & .093 \\
\hline Diagnosed hypertension, \% & 42.0 & 53.7 & & $0.68(0.49-0.95)$ & .024 \\
\hline Diagnosed high cholesterol, \% & 36.7 & 37.7 & & $0.94(0.68-1.31)$ & .72 \\
\hline Often feels depressed, \% & 27.7 & 17.2 & & $1.72(1.18-2.47)$ & .004 \\
\hline Mental health visit(s) in last year, \% & 19.2 & 10.5 & & $1.72(0.94-3.15)$ & .078 \\
\hline
\end{tabular}


Table 3. Reported Self-management by Smoking Status $(\mathrm{N}=1,352)$

\begin{tabular}{|c|c|c|c|c|c|}
\hline Self-Management & Smokers & Nonsmokers & $P$ Value & $\begin{array}{l}\text { Adjusted OR* } \\
\qquad(95 \% \mathrm{CI})\end{array}$ & $\begin{array}{l}\text { Adjusted } \\
P \text { Value* }\end{array}$ \\
\hline Check blood glucose $2+/ w k$, $\%$ & 59.0 & 67.2 & .03 & $0.66(0.47-0.91)$ & .013 \\
\hline Check feet $\geq 1 / w k, \%$ & 67.0 & 67.4 & .93 & $1.02(0.73-1.43)$ & .92 \\
\hline Follow special diet, \% & 47.3 & 54.0 & .09 & $0.82(0.59-1.12)$ & .21 \\
\hline Cheat on diet weekly, \% & 65.2 & 71.5 & .22 & $0.63(0.38-1.03)$ & .066 \\
\hline Will start special diet in next month, \% & 15.2 & 15.3 & .96 & $0.79(0.42-1.49)$ & .47 \\
\hline Take $A S A \geq 3 / w k, \%$ & 27.7 & 30.2 & .47 & $1.28(0.89-1.86)$ & .19 \\
\hline Always/usually takes diabetes medication as directed, \% & 76.6 & 81.8 & .09 & $0.77(0.52-1.15)$ & .20 \\
\hline Physical activity (d/wk) & $4.6 \pm 2.4\left(4.4^{*}\right)$ & $4.9 \pm 2.4(4.9 *)$ & .07 & & $<.001$ \\
\hline Will increase physical activity in next month, \% & 42.6 & 44.1 & .70 & $0.88(0.64-1.22)$ & .44 \\
\hline $\begin{array}{l}\text { Strongly feels able to do the things needed for } \\
\text { control, } \%\end{array}$ & 20.8 & 23.8 & .37 & $0.85(0.57-1.26)$ & .41 \\
\hline $\begin{array}{l}\text { Doctor often asks take some responsibility for } \\
\text { treatment, \% }\end{array}$ & 35.6 & 27.2 & .02 & $1.36(0.97-1.92)$ & .076 \\
\hline
\end{tabular}

significantly less likely to check their blood glucose levels more than once a week or to engage in daily physical activity, but were similar to nonsmokers on other measures of diabetes self-care. Table 4 evaluates use of services. Smokers with diabetes reported fewer medical visits, foot checks, eye examinations, and dental checkups. They also were significantly less likely to report having a regular diabetes care provider.

Table 5 shows that smokers were generally less likely to report strong support from their family and friends for specific aspects of diabetes self-care, although they also appeared to be less interested in that support. Smokers, however, were just as likely to report having an emotional bond with at least 1 other person, having someone they can talk to about important decisions or count on in an emergency, or someone who depends on them for help (data not shown). Despite being more likely to report often feeling sad or depressed, current smokers were no more likely than nonsmokers to blame diabetes for feeling life is difficult (18.6\% vs $16.8 \%)$, for feeling unhappy or depressed ( $11.7 \%$ vs $8.3 \%$ ), for feeling dissatisfied with life (9.6\% vs $7.1 \%)$, or for feeling not as good as others (6.4\% vs $7.9 \%)$. Also, controlling for reported frequent sad or depressed feelings had no effect on any of the above significant differences between smokers and nonsmokers.

\section{DISCUSSION}

These findings support the hypothesis that smokers with diabetes tend to be less actively involved in their diabetes care than are nonsmokers. After adjusting for demographic factors, diabetes patients who smoke were less likely to check their blood glucose levels frequently, exercise regularly, or receive a variety of medical services designed to improve diabetes care and prevent complications. Smokers appear to feel less support from family and friends, but they also have less interest in such support. In addition, they are less likely to report a regular diabetes care provider. In previous studies, ${ }^{27}$ having a regular provider of care has been a predictor of better diabetes care.

Compared with smokers without diabetes in the same population of patients, these smokers with diabetes were less interested in quitting. For example, a recent survey of smokers in the health plan used for this study found $26 \%$ of all adult smokers to be in preparation and only $30 \%$ in precontemplation (unpublished observations). This picture is also compatible with the relatively lower levels of readiness to quit smoking among these smokers with diabetes. Even so, the smokers with diabetes in this study were more ready to change than those in the study reported by Ruggiero et $\mathrm{al}^{21}: 20 \%$ vs $7 \%$ in preparation and $51 \%$ vs $58 \%$ in precontemplation.

Smokers with diabetes in this study were $60 \%$ more likely to report that they "often feel sad or depressed" compared with nonsmokers with diabetes, even after adjustment for relevant variables. Thus, it may be tempting to ascribe most of the differences noted above to depression, because it is well documented that both those with diabetes and smokers in general are more likely to report depression, and that smokers who are depressed have more difficulty quitting. ${ }^{28-32}$ Our question, however, is not a validated way to identify clinical depression. Unlike Ciechanowski et $\mathrm{al}_{1}{ }^{33}$ who found depression severity was associated with poorer adherence to diabetic regimens, we could find no clear relationship between these reports of often feeling depressed and either diabetes self-care practices or 
Table 4. Reported Medical Care by Smoking Status ( $\mathrm{N}=1352$ )

\begin{tabular}{|c|c|c|c|c|c|}
\hline Self-Management & Smokers & Nonsmokers & $P$ Value & $\begin{array}{c}\text { Adjusted OR* } \\
(95 \% \mathrm{CI})\end{array}$ & $\begin{array}{l}\text { Adjusted } \\
P \text { Value* }\end{array}$ \\
\hline Visits per year for diabetes care, No. & $2.5 \pm 1.7\left(2.7^{*}\right)$ & $2.8 \pm 1.6(3.0 *)$ & .02 & & $<.001$ \\
\hline At least 1 diabetes visit in $1 \mathrm{y}, \%$ & $87.2 \%$ & $91.9 \%$ & .035 & $0.51(0.31-0.83)$ & .008 \\
\hline $\mathrm{HbA}_{1 c}$ tests in past year, No. & $2.0 \pm 1.5\left(2.0^{*}\right)$ & $2.2 \pm 1.6\left(2.3^{*}\right)$ & .09 & & .004 \\
\hline At least $1 \mathrm{HbA}_{1 c}$ test in $1 \mathrm{y}_{1} \%$ & $80.8 \%$ & $83.8 \%$ & .32 & $0.66(0.44-1.01)$ & .053 \\
\hline At least 1 foot check in $1 \mathrm{y}, \%$ & $54.8 \%$ & $65.0 \%$ & .007 & $0.69(0.50-0.96)$ & .03 \\
\hline Dilated eye examination in $1 \mathrm{y}, \%$ & $51.6 \%$ & $63.8 \%$ & .001 & $0.66(0.48-0.91)$ & .01 \\
\hline Routine check-up in $1 \mathrm{y}, \%$ & $79.8 \%$ & $85.3 \%$ & .05 & $0.75(0.50-1.12)$ & .16 \\
\hline Cholesterol check in $1 \mathrm{y}, \%$ & $72.3 \%$ & $76.5 \%$ & .22 & $0.78(0.55-1.11)$ & .17 \\
\hline Influenza shot in $1 \mathrm{y}, \%$ & $57.4 \%$ & $65.2 \%$ & .04 & $0.95(0.67-1.32)$ & .74 \\
\hline Pneumonia shot ever, \% & $14.9 \%$ & $22.8 \%$ & .014 & $0.79(0.51-1.24)$ & .31 \\
\hline Dental check-up in $1 \mathrm{y}, \%$ & $59.0 \%$ & $70.5 \%$ & .002 & $0.59(0.43-0.83)$ & .002 \\
\hline $\begin{array}{l}1 \text { physician or nurse who takes care } \\
\text { of diabetes, } \%\end{array}$ & $82.5 \%$ & $89.8 \%$ & .003 & $0.58(0.38-0.90)$ & .015 \\
\hline
\end{tabular}

Table 5. Social Support by Smoking Status ( $N=1,352)$

\begin{tabular}{|c|c|c|c|c|c|}
\hline Help and Support & $\begin{array}{l}\text { Smokers } \\
(\%)\end{array}$ & $\begin{array}{c}\text { Nonsmokers } \\
(\%)\end{array}$ & $P$ Value & $\begin{array}{l}\text { Adjusted OR* } \\
\qquad(95 \% \mathrm{CI})\end{array}$ & $\begin{array}{l}\text { Adjusted } \\
P \text { Value* }\end{array}$ \\
\hline Excellent care from health professionals & 32.5 & 36.4 & .29 & $0.90(0.64-1.26)$ & .54 \\
\hline \multicolumn{6}{|l|}{ Family, friends support me } \\
\hline Following diet & 32.5 & 41.3 & .021 & $0.68(0.48-0.96)$ & .028 \\
\hline Taking medicine & 31.9 & 40.0 & .034 & $0.67(1.06-2.10)$ & .022 \\
\hline Caring for feet & 22.3 & 27.3 & .152 & $0.87(0.59-1.27)$ & .046 \\
\hline Physical activity & 25.5 & 36.9 & .003 & $0.58(0.40-0.83)$ & .003 \\
\hline Testing blood sugar & 28.2 & 33.7 & .138 & $0.76(0.54-1.08)$ & .130 \\
\hline Feelings about diabetes & 30.3 & 37.4 & .062 & $0.68(0.48-0.96)$ & .027 \\
\hline \multicolumn{6}{|l|}{ I want family and friend support for } \\
\hline Following diet & 27.1 & 34.0 & .062 & $0.63(0.44-0.90)$ & .012 \\
\hline Taking medicine & 16.5 & 23.0 & .045 & $0.62(0.41-0.95)$ & .029 \\
\hline Caring for feet & 16.5 & 19.6 & .320 & $0.82(0.54-1.26)$ & .37 \\
\hline Physical activity & 26.1 & 36.3 & .006 & $0.53(0.37-0.75)$ & $<.001$ \\
\hline Testing blood sugar & 20.7 & 24.0 & .330 & $0.74(0.50-1.09)$ & .13 \\
\hline Feelings about diabetes & 27.7 & 33.2 & .130 & $0.62(0.43-0.88)$ & .008 \\
\hline $\begin{array}{l}\text { I feel an emotional bond with at least } \\
1 \text { person (agree/strongly agree) }\end{array}$ & 85.1 & 82.7 & .40 & $1.12(0.71-1.76)$ & .63 \\
\hline
\end{tabular}

physical activity levels. Even the greater than usual proportion of smokers in precontemplation was not related to self-reported depression, suggesting that other characteristics of smokers might make them more resistant to managing both smoking and diabetes.

These findings are limited in that they are based on a relatively small group of smokers who responded to the survey and who are also health plan members in Minnesota. As such, they are primarily white, middle class, and already subject to a variety of tobacco reduction efforts from multiple sources. In addition, these findings are based almost entirely on self-report with its potential for bias. Although the response rate of completed questionnaires was fairly high $(74 \%)$, questions might be raised about whether nonresponders or the 213 who responded but did not complete the questionnaire were different from those analyzed. There are some data about nonresponders in these same clinic settings to suggest that they are more likely to be smokers but are otherwise similar to responders in most characteristics and in all measures of physician care for a variety of cardiovascular risk factors. ${ }^{34}$ The smoking rate among the 213 incomplete responders was identical to that of the complete responders, as were most 
of the frequencies that could be compared. Finally, the questionnaire did not include questions about the frequency and details of physician support for smoking cessation that would have clarified the extent to which the tobacco guideline was being followed.

Despite those limitations, these results suggest several clinical strategies that may help diabetes patients who smoke reduce serious risks of morbidity and mortality. First, clinicians can expect to find depression frequently in smokers and should be prepared to treat depression aggressively when it is identified. Preliminary studies suggest that antidepressant treatment of diabetes patients with depression might improve their glycemic control along with their depression. ${ }^{35}$

Second, regardless of whether depression is present, clinicians can expect a greater likelihood that smokers will be nonadherent to management and prevention, so creativity and close follow-up will be especially important for these patients. For example, these patients might need care management by nurses working in conjunction with their physicians, active follow-up if they do not appear for recommended visits or tests, and more aggressive efforts to manage all cardiovascular risk factors.

Finally, both clinicians and patients should realize that smoking cessation is 1 of the 2 most important ways to reduce macrovascular complications in patients with diabetes, the other being hypertension control. It is especially important that clinicians apply the recommendations of the US Public Health Service clinical guideline for treating tobacco use by consistently using the 5 As: ask, assess, advise, assist, and arrange. ${ }^{8}$ Strong evidence supports a strategy that includes a brief nonconfrontational discussion of smoking cessation at nearly every clinical encounter and, because so many of these smokers are not ready to quit, applying a brief, stage-matched intervention designed to move the smoker to the next readiness stage. ${ }^{36,37}$

Although $85 \%$ of smoking respondents did report receiving advice about smoking from a health professional at some time in their lives, it is unlikely that many received recommended assistance and follow-up arrangements unless their experience is quite different from that of smokers reported in the literature. ${ }^{38-40}$ The guideline also implies that before providing advice to quit, it is very important to assess the patient's readiness to quit, and a lack of plans to do so within the next 6 months defines the precontemplator. Such smokers tend to overestimate the problems of quitting and underestimate the benefits, so the clinician should help them to think about what will be better if they quit and how there are now many aids to quitting. Moving such a smoker to the contemplation stage (readiness to quit within the next 6 months) should be seen as a success, because it doubles the chance of quitting in that time frame. ${ }^{41}$ In addition to such clinical cessation support, it is likely that extra support is needed from health plans and medical groups, and the high costs of caring for the cardiovascular complications of diabetes suggest that such cessation support will be particularly cost-effective for those organizations bearing any financial risk. ${ }^{19}$

It is time to take smoking more seriously in our approach to patients with diabetes. Although it is important to improve glycemic control and to screen for microvascular complications, it may be even more important to identify major macrovascular risk factors and work with the patient and family to control them. Because of low readiness to change, smoking cessation may be difficult to achieve, but use of stage-based approaches, consistent and frequent support and follow-up, and liberal use of medications should increase success rates. The key is to make smoking cessation one of the highest priorities in diabetes control.

These data suggest that diabetes patients who smoke are more likely to report often feeling sad or depressed; but even after adjusting for this factor, they are less likely to be active in self-management or to comply with diabetes care recommendations. Thus, diabetic patients who smoke are special clinical challenges and are likely to require more creative and consistent interventions and support.

To read commentaries or to post a response to this article, see it online at http://www.annfammed.org/cgi/content/full/2/1/26.

Key words: Depression; diabetes mellitus; health maintenance organizations; practice guidelines; smoking

Submitted September 4, 2002; submitted, revised, January 8, 2003; accepted February 14, 2003.

Acknowledgments: Supported by a grant from the Centers for Disease Control and Prevention through the Minnesota Department of Health Diabetes Control Program.

\section{REFERENCES}

1. Mulhauser I. Smoking and diabetes. Diabet Med. 1990;7:10-15.

2. Muhlhauser I. Cigarette smoking and diabetes: an update. Diabet Med. 1994;11:336-343.

3. Haire-Joshu D, Glasgow RE, Tibbs TL. Smoking and diabetes. Diabetes Care. 1999;22:1887-1898.

4. Stamler J, Vaccaro O, Neaton J, Wentworth D. Diabetes, other risk factors, and 12-year cardiovascular mortality for men screened in the Multiple Risk Factor Intervention Trial. Diabetes Care. 1993;16:434-444.

5. Tuomilehto J, Rastenyte D, Jousilahti P, Sarti C, Vartiainen E. Diabetes mellitus as a risk factor for death from stroke: prospective study of the middle-aged Finnish population. Stroke. 1996;27:210-215.

6. Schernthaner G. Cardiovascular mortality and morbidity in type-2 diabetes mellitus. Diabetes Res Clin Pract. 1996;31:S3-S13. 
7. Chaturvedi N, Stevens L, Fuller JH. Which features of smoking determine mortality risk in former cigarette smokers with diabetes? Diabetes Care. 1997;20:1266-1272.

8. The Tobacco Use and Dependence Clinical Practice Guideline Panel. A clinical practice guideline for treating tobacco use and dependence: a US Public Health Service Report. JAMA. 2000;283:3244-3254.

9. Cromwell J, Bartosch WJ, Fiore MC, Hasselblad V, Baker T. Costeffectiveness of the clinical practice recommendations in the AHCPR guideline for smoking cessation. JAMA. 1997;278:1759-1766.

10. Canga N, De Irala J, Vara E, Duaso MJ, Ferrer A, Martinez-Gonzalez MA. Intervention study for smoking cessation in diabetic patients. Diabetes Care. 2000;23:1455-1460.

11. Malarcher AM, Ford ES, Nelson DE, et al. Trends in cigarette smoking and physicians' advice to quit smoking among people with diabetes in the U.S. Diabetes Care. 1995; 18:694-697.

12. American Diabetes Association. Smoking and diabetes. Diabetes Care. 2000;23:93-94.

13. Gilmer TP, O'Connor PJ, Manning WG, Rush WA. The cost to health plans of poor glycemic control. Diabetes Care. 1997;20:1-7.

14. O'Connor PJ, Spencer E, Woolf SH. Care of adults with type 2 diabetes mellitus: a review of the evidence. J Fam Pract. 1998;47(5 Suppl): S13-S22.

15. Savage PJ, Narayan KMV. Reducing cardiovascular complications of type 2 diabetes: a complex but achievable and affordable task. Diabetes Care. 1999;22:1769-1770.

16. Brun E, Nelson RG, Bennett PH, et al. Diabetes duration and causespecific specific mortality in the Verona Diabetes Study. Diabetes Care. 2000;23:1119-1123.

17. United Kingdom Prospective Diabetes Study Group. Intensive blood glucose control with sulfonylureas or insulin compared with conventional treatment and risk of complications in patients with type 2 diabetes. Lancet. 1998;352:837-853.

18. Egede LE, Zheng D. Modifiable cardiovascular risk factors in adults with diabetes: prevalence and missed opportunities for physician counseling. Arch Intern Med. 2002;162:427-433.

19. The CDC Diabetes Cost-Effectiveness Group. Cost-effectiveness of intensive glycemic control, intensified hypertension control, and serum cholesterol level reduction for type 2 diabetes. JAMA. 2002;287:2542-2551.

20. Boyle RG, O'Connor PJ, Pronk N, Tan A. Health behaviors of smokers, ex smokers, and never smokers in an HMO. Prev Med. 2000;31:177-182.

21. Ruggiero L, Rossi JS, Prochaska JO, et al. Smoking and diabetes: readiness for change and provider advice. Addict Behav. 1999;24:573-578.

22. Haire-Joshu D, Heady S, Thomas L, Schechtman K, Fisher EB Jr. Depressive symptomatology and smoking among persons with diabetes. Res Nurs Health. 1994;17:273-282.

23. O'Connor PJ, Rush WA, Pronk NP, Cherney LM. Identifying diabetes mellitus or heart disease among health maintenance organization members: sensitivity, specificity, predictive value, and cost of survey and database methods. Am J Manag Care. 1998;4:335-342.
24. Dillman DA. Mail and Telephone Surveys: The Total Design Method. New York, NY: John Wiley and Sons; 1978.

25. Klein R, Klein BE, Moss SE, DeMets DL, Kaufman I, Voss PS. Prevalence of diabetes mellitus in southern Wisconsin. Am J Epidemiol. 1984;119:54-56.

26. Huisman $\mathrm{TH}$, Henson JB, Wilson JB. A new high-performance liquid chromatographic procedure to quantitate hemoglobin $\mathrm{A} 1 \mathrm{C}$ and other minor hemoglobins in blood of normal, diabetic, and alcoholic individuals. J Lab Clin Med. 1983;102:163-73.

27. O'Connor PJ, Desai J, Rush WA, Cherney LM, Solberg LI, Bishop DB. Is having a regular provider of diabetes care related to intensity of care and glycemic control? J Fam Pract. 1998;47:290-297.

28. Anderson RJ, Freedland KE, Clouse RE, Lustman PJ. The prevalence of comorbid depression in adults with diabetes: a meta-analysis. Diabetes Care. 2001;24:1069-1078.

29. Anda RF, Williamson DF, Escobedo LG, Mast EE, Giovino GA, Remington PL. Depression and the dynamics of smoking: a national perspective. JAMA. 1990;264:1541-1545.

30. Glassman AH, Helzer JE, Covery LS, et al. Smoking, smoking cessation, and major depression. JAMA. 1990;264:1546-1549.

31. Giovino GA. Epidemiology of tobacco use and dependence. Epidemiol Rev. 1995:17:48-65.

32. Niaura R, Britt DM, Shadel WG, Goldstein M, Abrams D, Brown R. Symptoms of depression and survival experience among three samples of smokers trying to quit. Psychol Addict Behav. 2001;15:13-17.

33. Ciechanowski PS, Katon WJ, Russo JE. Depression and diabetes: impact of depressive symptoms on adherence, function, and costs. Arch Intern Med. 2000;160:3278-3285.

34. Solberg LI, Plane MB, Brown RL, Underbakke G, McBride PE. Nonresponse bias: does it affect measurement of clinician behavior? Med Care. 2002;40:347-352.

35. Lustman PJ, Freedland KE, Griffith LS, Clouse RE. Fluoxetine for depression in diabetes: a randomized double-blind placebo-controlled trial. Diabetes Care. 2000;23:618-623.

36. Prochaska JO. Strong and weak principles for progressing from precontemplation to action based on twelve problem behaviors. Health Psychol. 1994; 13:47-51

37. Prochaska JO, Goldstein MG. Process of smoking cessation: implications for clinicians. Clin Chest Med. 1991;12:727-735.

38. Goldstein MG, DePue JD, Monroe AD, et al. A population-based survey of physician smoking cessation counseling practices. Prev Med. 1998;27:720-729.

39. Thorndike AN, Rigotti NA, Stafford RS, Singer DE. National patterns in the treatment of smokers by physicians. JAMA. 1998;279:604-608.

40. Solberg LI, Davidson G, Alesci NL, Boyle RG, Magnan S. Physician smoking-cessation actions: are they dependent on insurance coverage or on patients? Am J Prev Med. 2002;23:160-165.

41. Prochaska JO. Why do we behave the way we do? Can J Cardiol. 1996; 11:20A-25A. 